\title{
Characterization of Leptospiral Serovars by Randomly Amplified Polymorphic DNA Fingerprinting
}

\author{
P. RAMADASS, ${ }^{*}$ S. MEERARANI, M. D. VENKATESHA, A. SENTHILKUMAR, AND K. NACHIMUTHU \\ Department of Animal Biotechnology, Madras Veterinary College, Tamil Nadu Veterinary \\ and Animal Sciences University, Chennai 600 007, Tamil Nadu, India
}

\begin{abstract}
Randomly amplified polymorphic DNA (RAPD) fingerprinting of 14 laboratory strains of leptospiral serovars (serovars australis, autumnalis, ballum, bataviae, canicola, grippotyphosa, hardjoprajitno, hebdomadis, icterohaemorrhagiae, javanica, pomona, pyrogenes, panama, and tarassovi) was carried out by using a pair of primers. Each serovar had a unique and distinct fingerprint pattern. DNAs of other bacterial species, including Escherichia coli, Pasteurella multocida, Salmonella spp., Pseudomonas spp., and Klebsiella spp., did not show any amplification. RAPD fingerprinting was found to be a rapid and sensitive method for serovar identification when it was compared to DNA restriction enzyme analysis, which produced a larger number of bands that made it more difficult to compare serovars.
\end{abstract}

Leptospirosis, which is caused by one of the nine or more species of pathogenic leptospires, is an important disease that affects livestock and humans. At present, there are more than 212 recognized serovars of leptospires divided into 23 serogroups (4). Conventionally, leptospirosis is diagnosed by detecting serum antibodies by the microscopic agglutination test or enzyme immunoassays. Direct demonstration of the presence of leptospires in biological samples is a definitive method of diagnosis, but large numbers of organisms need to be in a sample for direct demonstration. Isolation of leptospires from clinical specimens by culturing is labor-intensive and slow (too slow for clinical diagnosis), and samples may be from contaminated sources. Recently, tests based on DNA restriction enzyme analysis $(5,7)$ and DNA-DNA hybridization (6) and PCR assays (8) have been used to detect leptospires in clinical samples. Although DNA restriction enzyme analysis with different restriction enzymes is useful for identifying the leptospiral serovars, the large number of DNA fragments obtained makes differentiation between serovars difficult when only a few enzymes are used. Pulsed-field gel electrophoresis of Not I digests of leptospiral DNA (3) has facilitated comparisons between serovars because there are fewer DNA fragments. Recently, randomly amplified polymorphic DNA (RAPD) fingerprinting, which produces fewer DNA fragments, has been used for rapid identification of leptospires $(1,2)$. This method makes it easy to compare different serovars.

The goal of this work was to adapt the RAPD fingerprinting method so that it could be used to differentiate various leptospiral laboratory strains.

Bacterial strains and media. A total of 14 laboratory strains of leptospiral serovars were grown in EMJH media. The serovars represented were serovars autumnalis (strain Akiyami A), australis (strain Ballico), ballum (strain Mus 127), bataviae (strain Swart), canicola (strain Hond Utrecht IV), grippotyphosa (strain Moskva V), hardjo (strain Hardjoprajitno), hebdomadis (strain Hebdomadis), icterohaemarrhagiae (strain RGA), javanica (strain Veldrat Bat.46), pomona (strain Pomona), pyrogenes (strain Salinem), panama (strain CZ 214), and tarassovi (strain Perepelicin). Purified cultures of Escherichia coli, Pasteurella multocida, Salmonella spp., Pseudomonas spp., and Klebsiella spp. strains were also grown, and their DNAs were prepared for comparison. Leptospira cultures

\footnotetext{
${ }^{*}$ Corresponding author.
}

were grown in liquid EMJH media (Difco Laboratories, Detroit, Mich.) incubated at room temperature $\left(27\right.$ to $\left.30^{\circ} \mathrm{C}\right)$ for 7 to 10 days, and then DNAs were prepared.

DNA extraction. DNA samples were purified from the bacterial strains by treatment with lysozyme, sodium dodecyl sulfate, and protease (8). After overnight incubation at $55^{\circ} \mathrm{C}$ in a water bath, the DNA was purified by repeated extraction with phenol-chloroform-isoamyl alcohol (25:24:1, vol/vol/vol), followed by a final extraction with chloroform. The DNA was concentrated by precipitation with $99 \%$ ethanol.

RAPD fingerprinting. The RAPD fingerprinting method of Gerritsen et al. (2) was used with a few modifications. Briefly, each PCR was carried out in a mixture containing about $50 \mathrm{ng}$ of leptospiral chromosomal DNA, $10 \mathrm{mM}$ Tris- $\mathrm{HCl}$ (pH 9.0), $50 \mathrm{mM} \mathrm{KCl}, 4 \mathrm{mM} \mathrm{MgCl}$, each of the four deoxynucleoside triphosphates (Perkin-Elmer) at a concentration of $0.1 \mathrm{mM}$, each primer at a concentration of $300 \mathrm{pM}$, and $0.5 \mathrm{U}$ of $\mathrm{Taq}$ DNA polymerase. The mixture was overlaid with $50 \mu \mathrm{l}$ of mineral oil (Sigma), and the PCR was carried out in a Techne thermal cycler. The first two cycles consisted of denaturation at $95^{\circ} \mathrm{C}$ for $5 \mathrm{~min}$, annealing of primers for $5 \mathrm{~min}$ at $40^{\circ} \mathrm{C}$, and extension for $5 \mathrm{~min}$ at $72^{\circ} \mathrm{C}$. The subsequent 35 cycles consisted of denaturation for $1 \mathrm{~min}$ at $95^{\circ} \mathrm{C}$, annealing of primers for 1 min at $60^{\circ} \mathrm{C}$, and extension for $3 \mathrm{~min}$ at $72^{\circ} \mathrm{C}$, with a final extension step for $10 \mathrm{~min}$ during the last cycle. The PCR products were analyzed by electrophoresis on a $1.5 \%$ agarose gel at $100 \mathrm{~V}$ for 3 to $4 \mathrm{~h}$.

The primers used were primers B11 (CCGGAAGAAGGG GCGCCAT) and B12 (CGATTTAGAAGGACTTGCACAC) (2).

Results and Discussion. The primers used in this study, primers B11 and B12, produced characteristic band patterns for different serovars (Fig. 1 and 2). Fewer bands were produced than are produced in DNA restriction enzyme analyses. For most of the serovars, differentiating bands were observed between 300 and 1,000 bp. The serovar icterohaemorrhagiae, ballum, hebdomadis, pomona, tarassovi, australis, bataviae, and canicola strains produced more bands, whereas the serovar javanica, hardjoprajitno, and autumnalis strains produced fewer DNA bands. However, each serovar DNA band pattern was different and characteristic. DNAs from E. coli, P. multocida, Salmonella spp., Pseudomonas spp., and Klebsiella spp. strains did not exhibit any amplification with the primers used in this study, which confirmed the specificity of the primers.

An urgent need in leptospirosis diagnosis is a rapid, sensi- 


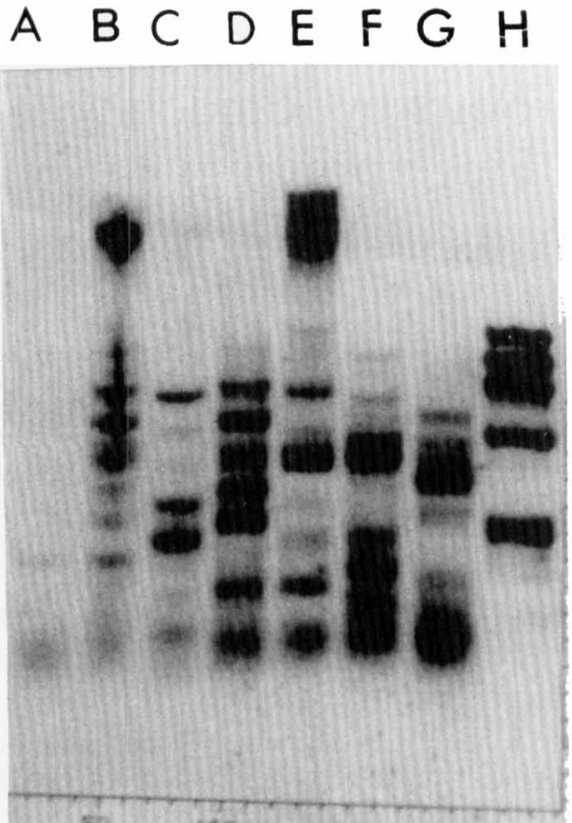

FIG. 1. RAPD fingerprints of leptospiral serovars and a molecular weight marker. Lane A, serovar autumnalis; lane B, serovar australis; lane C, serovar ballum; lane D, serovar bataviae; lane $\mathrm{E}$, serovar canicola; lane $\mathrm{F}$, serovar grippotyphosa; lane $\mathrm{G}$, serovar hebdomadis; lane $\mathrm{H}$, marker ( $\phi$ X174 HaeIII digest).

tive, reliable method for detecting leptospires and simultaneously identifying serovars involved in outbreaks of infection. The RAPD fingerprinting method fulfills all of the conditions for characterization of leptospiral serovars. The results of this study indicate that RAPD fingerprinting is one of the simpler methods for characterizing various serovars of leptospires. In this study, each of 14 serovars belonging to various serogroups and studied by the RAPD fingerprinting method produced a distinct pattern. This method produced bands that were distinct, reproducible, and serovar specific.

The results of this study are consistent with the work of Corney and coworkers (1), who found that RAPD fingerprinting was useful for identifying serovars hardjobovis, hardjoprajitno, pomona, balcanica, tarassovi, swajizak, kremastos, australis, and zanoni. These authors found that each serovar produced a unique RAPD profile. Gerritsen et al. (2) also used a RAPD method to rapidly identify leptospires belonging to serogroup Sejroe. In our study serovars belonging to different serogroups were tested by the RAPD analysis method, and each serovar produced a distinct band pattern.

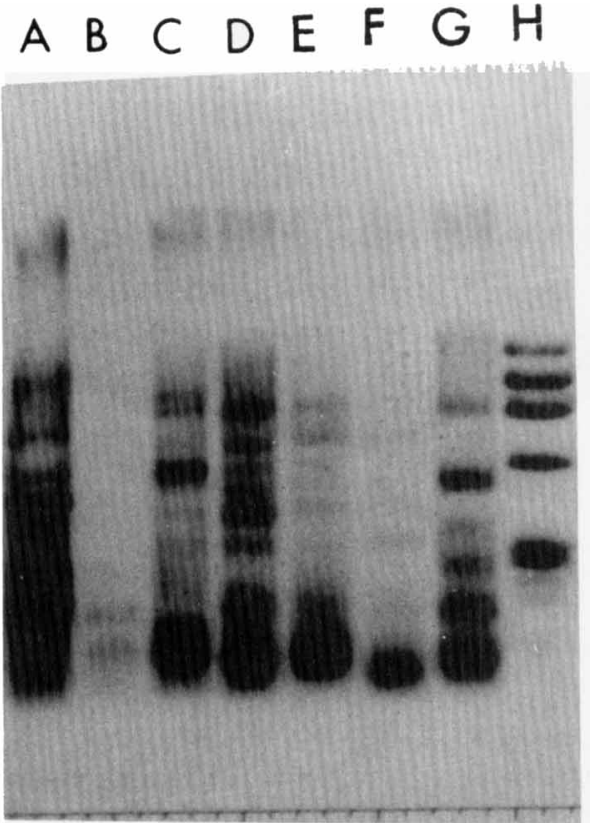

FIG. 2. RAPD fingerprints of leptospiral serovars and a molecular weigh marker. Lane A, serovar icterohaemorrhagiae; lane B, serovar javanica; lane C serovar panama; lane $\mathrm{D}$, serovar pomona; lane $\mathrm{E}$, serovar pyrogenes; lane $\mathrm{F}$ serovar hardjoprajitno; lane G, serovar tarassovi; lane H, marker ( $\phi$ X174 HaeII digest).

\section{REFERENCES}

1. Corney, B. G., J. Colley, S. P. Djordjevic, R. Whittington, and G. C. Graham 1993. Rapid identification of some Leptospira isolates from cattle by randomly amplified polymorphic DNA fingerprinting. J. Clin. Microbiol. 31:2927-2932.

2. Gerritsen, M. A., M. A. Smits, and T. Olyhoek. 1995. RAPD fingerprinting for rapid identification of leptospires of serogroup Sejroe. J. Med. Microbiol. 42:336-339.

3. Hermann, J. L., E. Bellenger, P. Perolat, G. Baranton, and I. Saint Girons. 1992. Pulse-field gel electrophoresis of NotI digests of leptospiral DNA: a new rapid method of serovar identification. J. Clin. Microbiol. 30:1696-1702.

4. Kmety, E., and H. Dikken. 1988. Revised list of Leptospira serovars. University of Groningen, Groningen, The Netherlands.

5. Marshall, R. B., B. E. Wilton, and A. J. Robinson. 1981. Identification of Leptospira serovars by restriction endonuclease analysis. J. Med. Microbiol. 14:163-166.

6. Ramadass, P., B. D. W. Jarvis, C. J. Corner, D. Perry, and R. B. Marshall. 1992. Genetic characterization of pathogenic leptospira species by DNA hybridization. Int J Syst Bacteriol 42:215-219.

7. Thiermann, A. B., A. L. Handsaker, S. L. Moseley, and B. Kingscotte. 1985 New method for classification of leptospiral isolates belonging to serogroup Pomona by restriction endonuclease analysis: serovar kennewickci. J. Clin. Microbiol. 21:585-587.

8. Van Eys, G. J. J. M., C. Gravekamp, M. J. Gerritsen, W. Quint, M. T. E Cornelissen, J. Ter Schegget, and W. J. Terpstra. 1989. Detection of leptospira in urine by polymerase chain reaction. J. Clin. Microbiol. 27:2258-2262. 